\title{
Phenotypic and Start Codon Targeted (SCoT) polymorphism reveals the genetic variation of Crataegus bretschneideri C. K. Schneid. and related species in China
}

\section{Xiao Zhang}

Shenyang Agricultural University College of Horticulture

\section{Xinyu Sun}

Tonghua Horticultural Institute

\section{Jian Wang}

Shenyang Agricultural University College of Horticulture

\section{Miliao Xue}

Shenyang Agricultural University College of Horticulture

Chao Sun

Shenyang Agricultural University College of Horticulture

Wenxuan Dong ( $\sim$ dongwx63@syau.edu.cn )

Shenyang Agricultural University College of Horticulture https://orcid.org/0000-0002-3684-8914

\section{Research Article}

Keywords: Crataegus bretschnesideri C. K. Schneid., Related Crataegus species, Genetic variation, Phenotypic trait, SCoT marker, Population structure

Posted Date: February 1st, 2022

DOI: https://doi.org/10.21203/rs.3.rs-1272845/v1

License: (a) (1) This work is licensed under a Creative Commons Attribution 4.0 International License. Read Full License 


\section{Abstract}

Crataegus bretschnesideri C. K. Schneid. originated in Northeast China, it has excellent characteristics of cold resistance and early maturity. However, the taxonomic status of $C$. bretschnesideri has been controversial due to the intra-specific hybridization and apomixes. Comparative assessment of phenotypic and molecular evaluations used to explore genetic diversity of $C$. bretschneideri and relative species. Qualitative and quantitative traits of $C$. bretschneideri and relative species were evaluated. Genetic diversity and population structure of several Crataegus species were analyzed by thirteen reported and five newly designed SCoT markers. Leaf traits of Crataegus had a higher Shannon-wiener index than fruit and flower traits; Fruit contained diverse traits among seven Crataegus species by principal component analysis. SCoT markers amplified 148 polymorphic bands with $94.87 \%$ polymorphic loci. Crataegus individuals clustered into five clades, and $C$. bretschneideri had a closer relationship with $C$. pinnatifida Bge. and $C$. hupehensis Sarg.. Population structure suggested that investigated the mixed gene pool appeared in $C$. bretschneideri. There had variation among Crataegus species, and part of the $C$. bretschneideri individuals may be a hybrid origin compared to the phenotypic and molecular evaluations. Newly designed SCoT markers were practical for Crataegus diversity analyses.

\section{Introduction}

Crataegus is an ancient plant genus belonging to Rosaceae, which originated in the Cenozoic (Zhao \& Feng, 1996). Crataegus fruit contains several flavonoids, phenols, oligoprocyanidins, and other active substances with medicinal value (T.A. Dickinson et al., 2014). Laboratory tests and clinical trials have proved the preventive and therapeutic effects of active substances in Crataegus on cardiovascular diseases (Edwards, Brown, Talent, Dickinson, \& Shipley, 2012). Several cultivated and wild species of Crataegus originated in China (Hong \& Blackmore, 2015). Hawthorn cultivation in China has more than 1700 years of history, and long-term cultivation and selection have formed a rich variety of types (Zhao \& Feng, 1996). There are eighteen species and six varieties of Crataegus widely distributed in China (Zhao \& Feng, 1996). There is another view that twenty species, seven varieties, and one variant of Crataegus (Dong \& Li, 2015). C. bretschneideri is one of cultivars that originated in northeast China, which has the characteristics of early maturity and cold resistance (Dong \& $\mathrm{Li}$, 2015). However, since phenotypic traits of $C$. bretschneideri are similar to $C$. pinnatifida (Fig. 1), its classification status is not very clear. It is not conducive to further conservation and utilization of $C$. bretschneideri germplasm resources.

Phenotypic traits are essential indices to identify Crataegus species (Timothy A Dickinson, Belaoussoff, Love, \& Muniyamma, 1996). Leaf morphological changes, leaf shape, and other leaf traits are widely used in the study of inter-specific and intra-specific relationships of Crataegus (J. Phipps \& Dvorsky, 2008). Patical hawthorns have identified the inter-species differences of their phenotypic traits (Jiang \& Dong, 2009). Dai et al. (2008) and Wu et al. (2008) analysed eight species and two varieties of Crataegus by three markers, including ISSR (Inter-Simple Sequence Repeat) markers, cpDNA PCR-RFLP (Polymerase Chain Reaction Restriction Fragment Length Polymorphism of chloroplast DNA), and cpSSR (chloroplast Simple Sequence Repeats). Liu et al. (2016) used ISSR markers to analyse the genetic relationships among $C$. altaica (Loud.) Lange, $C$. songorica Pall. and $C$. pinnatifida. In addition, studies have increasingly combined phenotypic traits with molecular markers to analyse the genetic diversity of Crataegus (Betancourt-Olvera, Nieto-Ángel, Urbano, \& González- 
Andrés, 2018; Sheng et al., 2017). Phenotypic and molecular evaluations of these studies revealed that there has considerable variation among different Crataegus species.

Extensive efforts are made to develop practical molecular tools and integrate phenotypic analysis to the molecular assessment of Crataegus genetic diversity. Start Codon Targeted polymorphism (SCoT) is a single primer designed for the conserved flanking sequence of the ATG initiation codon, and the amplified fragments tend to be candidate functional genes (Collard \& Mackill, 2008). SCoT marker includes many advantages, such as fewer steps, a simple primer design process, strong universality, low requirements for DNA quality, rich genetic information, and high polymorphism (Long et al., 2015). As a new type of marker, it has been widely used for genetic diversity, phylogenetic relationship analysis, and even germplasm identification in diverse plant species (Igwe et al., 2017; Saboori et al., 2020; Xiao et al., 2020). The present study used practical SCoT markers and phenotypic traits to explore the genetic difference behind $C$. bretschneideri and related species.

\section{Materials And Methods}

\section{Plant materials}

During the 2019 season, we picked leaves, flowers, and mature fruits of seven Crataegus species native to China from the National Fruit-tree Germplasm Resources - Shenyang Hawthorn Repository $\left(41^{\circ} 49^{\prime} \mathrm{N}, 123^{\circ} 34^{\prime} \mathrm{E}\right)$ at Shenyang Agricultural University from May to October, including $C$. bretschneideri (C. bre), C. maximowiczii (C. max), C. sanguinea (C. san), C. pinnatifida (C. pin), C. hupehensis (C. hup), C. scabrifolia (C. sca) and C. altaica (C. alt) (Table 1), which Prof. Dong and Ph.D. Zhang identified according to the pictures and descriptions of phenotypic traits in "China Fruit-plant Monograph-Hawthorn (Crataegus) Flora" (Zhao \& Feng, 1996). We randomly collected twenty leaves, flowers, and fruits from three trees for each individual.

\section{Phenotypic traits measurements}

We used twenty leaves, flowers, and mature fruits for each of $C$. bre and other species for phenotypic trait measurements. Methods followed the scales for evaluating crop germplasm resources of hawthorn (Dong, 2013). Qualitative traits of Crataegus resources include twenty-one items such as leaf color, stipule shape, petal shape, petal color, fruit skin color, flesh color. Quantitative traits of Crataegus resources include twelve items such as leaf length, leaf width, petiole length, corolla diameter, flower number of inflorescence, and number of pistils and stamens, fruit weight, fruit hardness, fruit vertical diameter, fruit horizontal diameter, and fruit shape index (calculated as the ratio of fruit vertical to horizontal diameter). Scales of qualitative traits were summarized in supplementary Table S1. Fruit weight, leaf length, leaf width, petiole length, fruit vertical and horizontal diameter of Crataegus were measured by electronic balance $(200 \mathrm{~g} \pm 0.1 \mathrm{~g})$, digital vernier calipers $(0-150 \mathrm{~mm} \pm 0.02 \mathrm{~mm})$. Fruit hardness was evaluated using a computer-controlled texture analyzer TA.XT plus (Stable Micro System, Godalming, UK), according to the protocol described by Zhang et al. (Zhang et al., 2019).

\section{Phenotypic data analysis}

Phenotypic traits were evaluated achieved in random samples of twenty of each Crataegus resource. We used the "Tukey" method in SPSS 20.0 (IBM, US) to calculate the mean and variance of quantitative trait data. Otherwise, we applied the "vegan" package of R v4.0.3 software to analyse the Shannon-wiener index of 
qualitative traits data. Cluster and principal component analyses of phenotypic traits were using the Origin 2019b software (https://www.originlab.com/), a proprietary computer program for interactive scientific graphics and data analysis. Phenotypic traits data were standardized by subtracting the mean and dividing the result by the standard deviation, this was to reduce the effects of different measurement scales on various traits. Hierarchical cluster analysis of standardized data used the group average's method coupled with the Euclidean distance method. The distance between two clusters was determined as the average distance between all pairs of objects in the different clusters.

\section{DNA extraction and SCOT assays}

Fresh leaves of seven Crataegus species were frozen in liquid nitrogen and stored at $-80^{\circ} \mathrm{C}$ for DNA extraction. We ground one gram of frozen leaf material for genomic DNA extraction using cetyl-trimethylammonium bromide method (Du et al., 2019). Genotyping was performed using 13 SCoT primers selected from Collard and Mackill's data (Collard \& Mackill, 2008). We designed five new primers $\left(\mathrm{SCoTH}_{1-5}\right)$ for Crataegus genetic diversity analyses based on the design role. All primers and Tm are listed in Table 2. PCR amplification was performed with a final volume of $10 \mu \mathrm{L}$ reaction mixture consisting of $3 \mu \mathrm{L}$ template DNA (40-50 ng), $5 \mu \mathrm{L}$ of TaKaRa Ex Taq ${ }^{\circledR}\left(\right.$ RR001A), and $2 \mu \mathrm{L}$ primers. PCR conditions were as follows: initial denaturation at $94^{\circ} \mathrm{C}$ for 5 min followed by 30 cycles of $1 \mathrm{~min}$ at $94^{\circ} \mathrm{C}, 1 \mathrm{~min}$ at $54-64^{\circ} \mathrm{C}, 1 \mathrm{~min}$ at $72^{\circ} \mathrm{C}$, and a final extension of $5 \mathrm{~min}$ at $72^{\circ} \mathrm{C}$. PCR amplification was carried out in a Thermal Cycler (Applied Biosystems, USA). PCR products were separated on a $1.5 \%$ agarose gel in 5 X TBE buffer.

\section{Molecular data analysis}

SCOT markers generated data matrices by scoring (1) for presence and ( 0 ) for absence (supplementary Table S2). Genetic similarities based on Jaccard's coefficients were calculated using the SIMQUAL program with the Numerical Taxonomy Multivariate Analysis System in NTsys-PC v2.0 software (Rohlf, 2000). The resulting genetic similarity indices generated the cluster tree through the Un-weighted Pair-Group Method with Arithmetic average (UPGMA). The Mantel correlation test of genetic similarity was applied to the matrix table of each marker by matrix comparison plot. Moreover, a series of diversity parameters were calculated from molecular data by referencing Bhattacharyya et al. (Bhattacharyya, Kumaria, Kumar, \& Tandon, 2013) using Popgene 3.2 (Yeh, Yang, \& Boyle, 1999). Diversity parameters include the Number of Polymorphic Loci (NPL), Percentage of Polymorphic Loci (PPL), the observed number of alleles $\left(N_{\mathrm{a}}\right)$, effective numbers of alleles $\left(N_{\mathrm{e}}\right)$, Neis gene diversity $(H)$, total genetic diversity of the sample population $(H t)$, genetic diversity within population $(H s)$, Shannon's information index $(I)$, mean coefficient of gene differentiation $\left(G_{\mathrm{st}}\right)$, an estimate of gene flow $\left(N_{\mathrm{m}}=\right.$ $\left.0.5 \times\left(1-G_{\mathrm{st}}\right) \div G_{\mathrm{st}}\right)$. We used Nei's unbiased measures of genetic identity to measure the similarity among alleles. We also used genetic distance was used to measure the genetic differentiation between groups of the same species. Principal Coordinate Analysis (PCoA) was performed using GenAlEx 6.41 software (Peakall \& Smouse, 2006) and OmicStudio tools v2.1 (https://www.omicstudio.cn/tool/24) to reveal genetic clusters among the individuals. Structure v2.3.4 software (Hubisz, Falush, Stephens, \& Pritchard, 2009) statistical tool was used with an Evanno correction using Structure Harvester (Earl \& vonHoldt, 2012). The structure was run ten times for each value from 1 to 7 to determine the population's most likely number of ancestral Kinships $(K)$.

\section{Results}




\section{Phenotypic diversity analysis of seven Crataegus species}

We assessed the genetic diversity of seven Crataegus resources (C. bre, C. max, C. san, C. pin, C. hup, C. sca, and $C$. alt) based on phenotypic traits and SCoT markers. Phenotypic traits of these Crataegus resources represented a high level of diversity (Fig. 1, supplementary Table S3). Several morphological traits of Crataegus resources were analysed statistically (supplementary Table S4). Among leaf traits of all test materials, Shannon-wiener indexes of leaf shape, leaf margin, and leaf base shape were 1.4, 1.3, and 1.4, indicating leaf traits contained highest diversity. $19.4 \%$ of leaf shape was ovate, $36.1 \%$ were wide ovate, $27.8 \%$ were triangular ovate, $11.1 \%$ were ovate-lanceolate. $5.6 \%$ of leaf base shape were truncate, $30.6 \%$ were round, $38.9 \%$ were broad cuneate, $19.4 \%$ were cuneate, and $5.6 \%$ were decurrence cuneate. The variable trait of Crataegus flowers was the pedicel surface. Shannon-wiener index was $1.3,38.9 \%$ were glabrous, $13.9 \%$ were less woolly, $36.1 \%$ were woolly and $11.1 \%$ were extremely woolly. The Shannon-wiener indexes of fruit dot quantity, fruit surface trait, and calyx tube shape were 1.0, 1.1, 1.0, which showed high diversity. For fruit dot quantity, 27.8\% of mature fruit had very few surface dots, $8.3 \%$ had few dots, $58.3 \%$ had intermediate number dots, and $5.6 \%$ had many dots. In general, leaf and fruit traits had relatively rich diversity among different Crataegus species.

Quantitative traits of these Crataegus resources were further analysed statistically (Fig. 2, supplementary Table S3, Table S4). Variation coefficients of twelve metric traits were $10.37 \%-51.98 \%$. The order of the degree of diversity was flower number of inflorescence $>$ fruit weight $>$ petiole length $>$ fruit firmness $>$ fruit horizontal diameter $>$ fruit vertical diameter $>$ pistil number $>$ corolla diameter $>$ leaf width $>$ leaf length $>$ stamen number $>$ fruit shape index. The fruit of $\mathrm{MSZ3H}(C . \max , 0.4 \mathrm{~g})$ was the lightest, and the heaviest was $\mathrm{MHL}(C$. hup, 6.2 g). HBSZ2HN (C. hup) had the highest number of flowers per inflorescence (30.25), while WTSSLH (C. pin) had the fewest (4.4). QJX (C. pin) had the longest petiole $(47.43 \mathrm{~mm})$, while MSZ2H (C. max) had the shortest petiole $(9.82 \mathrm{~mm})$. The hardest fruit was QJX (C. pin), and the softest fruit was LNSZ1H (C. san). Compared with other traits, the difference in stamen number or fruit shape indices among several Crataegus species was smaller (supplementary Table S3).

Principal component analysis transformed phenotypic traits data of leaf, flower, and fruit into fewer dimensions, which serve as summaries of features (supplementary Table S5). The contribution rate of the first principal component was $23.82 \%$, and the main eigenvectors included fruit dots quantity. The contribution rate of the second principal component was $15.47 \%$, and the main eigenvectors had fruit weight, fruit vertical diameter, and horizontal diameter. These two main components contained important diverse traits among $C$. bre, C. max, C. san, C. pin, C. hup, C. sca, and C. alt.

We implemented hierarchical cluster analysis to find similar groups of individuals among different Crataegus species using phenotypic data based on the Euclidean distance method. Leaf and fruit traits data grouped seven species into four clades (Fig. 3A, C), and all traits data grouped seven species into five main clades (Fig. 3D). Clade 1 included fourteen $C$. bre resources and NMGSLH, YP6H, and WTSSLH (C. pin), clade 2 included 1541SLH, MDFSLH, YR5H (C. pin), and HBSZ2H (C. hup), clade 3 included YNSZ1H, YNSZ2H, YNSZ3H (C. sca), and HBSZ3H (C. hup), clade 4 included MSZ2H, MSZ3H (C. max) and LNSZ1H, LNSZ2H, LNSZ3H (C. san), clade 5 included AETSZ2H, AETSZ3H (C. alt). The scale of dissimilarity values of the Euclidian coefficient ranged between 7.31 and 45.96 which reflected the high level of diversity among Crataegus resources. Phenotypic traits of leaf, flower, and fruit between $C$. bre, and $C$. pin were similar. Thus, $C$. bre and $C$. pin 
resources were clustered into the same clade. Additionally, C. max and C. san were pressed into clade 4, because the leaf and fruit traits data were very similar and different from other Crataegus species.

\section{Molecular diversity analysis of Crataegus individuals based on SCOT data}

Eighteen SCoT markers were able to amplify several bands across the 36 Crataegus resources, including $C$. sca and $C$. alt (supplementary Fig. S1, Table S2). According to the principle of SCoT primers, we designed five new SCoT primers $\left(\mathrm{SCOTH}_{1-5}\right)$ for the molecular diversity analysis of Crataegus (Table 2). A series of parameters were calculated from molecular data to assess the level of diversity among the Crataegus resources (Table 3). All the SCoT markers amplified 148 polymorphic bands, the percentage of polymorphic loci was $94.87 \%$. In this regard, polymorphic bands ranged from 3 to 16, while the percentage of polymorphic loci ranged from $62.5 \%$ to $100 \%$. The highest polymorphism information content $(P I C)$ and resolving power $(R P)$ values were 0.50 and 9.88, respectively, generated by SCoT22. Moreover, the percentage of polymorphic loci of 5 new SCoT markers was $100 \%$, and $P I C$ and $R P$ ranged from 0.44 to 0.50 and 3.43 to 4.92 , respectively.

Moreover, several diverse parameters were analysed from SCoT data among different Crataegus species (Table 4). The observed number of alleles $\left(N_{\mathrm{a}}\right)$ and the effective number of alleles $\left(N_{\mathrm{e}}\right)$ varied from 1.18 to 1.64 and 1.14 to 1.45 , respectively. Neis gene diversity $(H)$ and Shannon's Information index $(I)$ ranged from 0.08 to 0.25 , with an overall diversity of 0.33 and from 0.11 to 0.36 with an average value of 0.26 , respectively. The percentage of polymorphic loci $(P P L)$ was expected to be in the range of $17.95 \%$ to $64.11 \%$. The total variability $\left(H_{\mathrm{t}}\right)$ and variability within population $\left(H_{\mathrm{s}}\right)$ were 0.34 and 0.18 , respectively. The diversity among populations $\left(G_{\mathrm{st}}\right)$ and gene flow $\left(N_{\mathrm{m}}\right)$ values were 0.58 and 0.36 , respectively. Nei's unbiased measures of genetic identity, and genetic distance among the population have also been evaluated (Table 5). Nei's genetic distance ranged from 0.1069 to 0.5440 , while Nei's genetic identity ranged from 0.5804 to 0.8986 . C. pin and C. hup were closely related to 0.8986 identities and 0.1069 distance. $C$. bre and $C$. pin were also closely related to 0.8655 identities and 0.1444 distance.

Thirty-six Crataegus resources were clustered into four main clades using the UPGMA method (Fig. 4, supplementary Table S6, S7). Clade I contained fourteen $C$. bre resources and HBSZ2H (C. hup), while Clade II consisted of a total of eight $C$. pin resources and $C$. hup (HBSZ3H, XPZM, MHL). These two clades were separated at approximately 0.67 similarity. Clade III gathered four $C$. sca resources, while clade IV had two $C$. max and three $C$. san resources. Clade III was separated from Clade I - II at approximately 0.63 similarity, while clade IV was divided with Clade III at approximately 0.61 similarity. C. max and C. san were closely linked to approximately 0.75 similarity. AETSZ2H and AETSZ3H were far from other Crataegus resources. The closest Crataegus individuals were JF4H and FLH at 0.94 similarity.

Principal Coordinate Analysis (PCoA) based on SCoT data revealed the relationship among Crataegus individuals (Fig. 5, supplementary Table S8). The two-dimensional projection of varieties along the first two main axes revealed the genetic relationships among Crataegus individuals $(R=0.8533, P=0.001)$. The closer distance between the two individuals represented fewer differences. The total percentage of variation resulting from PCoA was $19.49 \%$ and $17.5 \%$, given by PC1 and PC2, respectively. Eleven $C$. bre individuals had a close relationship with one $C$. pin, four $C$. bre individuals had a close relationship with four $C$. pin and one $C$. hup individuals. 
Population structure investigated the diversity among Crataegus individuals. $\triangle K$ analysis revealed that five populations $(K=5)$ represented the best model for 36 individuals (Fig. 6, supplementary Fig. S2). The results showed that when $K=3-6, C$. max and $C$. san were mainly in the yellow gene pool, and $C$. pin and $C$. hup were primarily in the blue gene pool (Fig. 6). Population structures of $C$. max and $C$. san were very similar. Thus, relationships between these two Crataegus species were closer. Similar results were observed between $C$. pin and $C$. hup. Otherwise, a mixed gene pool appeared in $C$. bre, which mixed a small yellow and blue gene pool. $C$. bre showed partial gene exchange and revealed its possible hybrid origin.

\section{Discussion}

\section{Phenotypic diversity analyses of Crataegus species}

Due to long-term adaptation to environmental changes, wild species related to the cultivated species have formed and accumulated rich genetic variety and excellent gene resources in the process of evolution ( $\mathrm{Lu}$, 2014). Because of the importance of related species for hawthorn breeding programs, it is necessary to implement genetic diversity analysis of Crataegus fruit tree resources in China to provide the basis for botanical converation, and utilization of germplasm resources.

The traditional classification of Crataegus species is based on morphological characteristics and geographical distribution. The phenomena of apomixes, inter-specific hybridization, and polyploidy often exist widely in Crataegus. These have led to high genetic differences in morphological characteristics (Dönmez, 2008) and increased difficulties in classifying Crataegus species. Flowering or fruiting periods could only reflect unique characteristics of some Crataegus, which makes their identification and classification more complicated (Christensen, 1992, Phipps, 2005). PCA of the phenotypic diversity of $C$. pentagyna Waldst. \& Kit. ex Willd. and C. monogyna Jacq. from north-eastern parts of Iran revealed that fruit traits contributed the most to accession diversity, followed by leaf traits (Khadivi et al., 2019). Du et al. (2019) separated six Crataegus species into four groups based on leaf and mature fruit traits. $C$. bre were assigned to a group with deep leaves and big fruits. In this study, leaf and fruit traits had relatively rich diversity among different Crataegus species. $C$. bre and $C$. pin resources were clustered into the same clade based on the leaf and flower traits. However, $C$. bre individuals were clustered into a single groups according to the unique fruit traits (Fig. 3 ). The above results indicate that $C$. bre has unique fruit characters. However, it is not possible to directly identify $C$. bre resources only by phenotypic traits.

\section{SCOT markers used in genetic diversity analysis}

SCoT markers contain rich genetic information and high polymorphism. For the genetic diversity study of Chrysanthemum morifolium cultivars, 32 SCoT primers amplified $73.1 \%$ (SCoT24) polymorphic bands at least, and $P I C$ values of these primers were at least 0.950 (SCoT19) (Feng et al., 2016). Igwe et al. (2017) demonstrated that SCoT markers were more efficient than ISSR for genetic diversity studies in Vigna unguiculata (L.) Walp. SCoT marker was more informative with higher discriminating power than RAPD, ISSR, and iPBS (inter Primer Binding Site) markers (Amom et al., 2020). In particular, SCoT13 had the highest Polymorphism and PIC value when amplified for accessions of landraces chickpea (Cicer arietinum) (Pakseresht et al., 2013). SCoT12 and SCoT16 were the most polymorphic markers among the 15 SCoT markers when 164 wild plants were amplified in fourteen ecologically different natural populations of the 
Crataegus pontica. The high level of genetic variation that exists among and within 201 accessions of the genus Crataegus was reflected by $0.02-0.62$ genetic similarity, 13 SCoT primers produced 115 polymorphic fragments, and the polymorphism percentage bands of $S \operatorname{CoT} 1,7,11,14$, and $20-23$ were more than 90\% (Emami, et al., 2018). Our results indicated that 18 SCoT markers amplified 148 polymorphic bands in 36 Crataegus individuals, the percentage of the polymorphic loci ranged from $62.5 \%$ to $100 \%$, with a mean value of $94.87 \%$ (Table 3). The highest PIC and $R P$ values of SCoT were 0.50 and 9.88 , respectively, generated by SCoT22. Moreover, the percentage of the polymorphic band of five new SCoT markers was $100 \%$, and PIC and $R P$ ranged from 0.44 to 0.50 and 3.43 to 4.92 , respectively. Based on SCoT data, we generated a similar phylogenetic tree to SLAF-seq (Specific-Locus Amplified Fragment sequencing) (Du et al., 2019), clustering $C$. bre and $C$. pin into the closer Clade. Otherwise, SCOT markers reduce the analysis cost and time. These results revealed that SCoT markers, especially SCoT22, SCoT32, SCoTH 2 , SCoTH 3 , SCoTH 5 markers were efficient, informative, and polymorphic for molecular diversity studies in the Crataegus species in China's native germplasm.

\section{Inter-specific hybridization of Crataegus species}

Inter-specific hybridization can promote the formation of new hawthorn species (Phipps, 2014). The natural hybridization of different hawthorn species often occurs in the overlap region of geographical distribution, leading to hawthorn germplasm's genetic diversity (Talent \& Dickinson, 2007). Researchers have provided evidence for natural hybridization in the evolution of hawthorn plants at the molecular level (Lo et al., 2010). In this study, $C$. bre was similar to $C$. pin on phenotypic traits. The plant list (http://www.theplantlist.org/tpl1.1/record/rjp-18388) and Plants of the World online (http://www.plantsoftheworldonline.org/taxon/urn:Isid:ipni.org:names:723046-1) had recorded: $C$. bre was a synonym of $C$. pin. Cluster results of RAPD showed that $C$. bre was a variety or subspecies of $C$. pin (Dai et al., 2008). However, Guo et al. (1995) and Wu et al. (2008) considered C. bre was independent Crataegus species that had a close relationship with $C$. pin. ISSR results confirmed this view (Han et al., 2009). Structure and TreeMix analysis showed that $C$. bre might have a hybrid origin (Du et al., 2019). Recently, chloroplast genomes of $C$. pin, $C$. bre, $C$. max, and $C$. pinnatifida var. major N.E.Br. were sequenced, and results revealed that $C$. max was the maternal origin of $C$. bre (Hu et al., 2021). In this study, a mixed gene pool appeared in $C$. bre containing a small amount of yellow and blue pools by population structure analysis (Fig. 6). C. bre showed partial gene exchange among $C$. $\max , C$. san, $C$. pin, and $C$. hup. Otherwise, a total of eight $C$. pin resources and C. hup (HBSZ3H, XPZM, MHL) clustered into Clade II (Fig. 4). C. pin and C. hup had similar gene pools when $K=$ 3- 6 (Fig. 6). C. hup differentiated at $6.86 \mathrm{Ma}$, while C. pin differentiated at 1.23 Ma (Du et al., 2019). Thus, further studies are needed to determine the relationship between $C$. pin and $C$. hup.

\section{Conclusions}

Our results revealed that SCoT markers were informative and practical for the study of Crataegus genetic diversity. $C$. bretschneideri may be a hybrid origin compared to the phenotypic and molecular evaluations.

\section{Declarations}

\section{Funding}


This work was supported by "The Conservation and Utilization of Crop Germplasm Resource - Hawthorn (Project \# 19190178).

\section{Competing Interests}

All the author declare they have no financial interests.

\section{Author Contributions}

Conceptualization, X.Z. and W.D., methodology, X.S., software, X.Z., validation, X.Z., X.S. and J.W., formal analysis, J.W., resources, W.D., data curation, M.X. and C.S., writing-original draft preparation, X.Z., writingreview and editing, X.Z. and W.D., funding acquisition, W.D. All authors have read and agreed to the published version of the manuscript.

\section{Data Availability}

The data presented in this study are available in supplementary material.

\section{References}

1. Amom T, Tikendra L, Apana N, Goutam M, Sonia P, Koijam AS, Nongdam P (2020) Efficiency of RAPD, ISSR, iPBS, SCOT and phytochemical markers in the genetic relationship study of five native and economical important bamboos of North-East India. Phytochemistry 174: 112330. https://doi.org/10.1016/j.phytochem.2020.112330

2. Betancourt-Olvera M, Nieto-Ángel R, Urbano B, González-Andrés F (2018) Analysis of the biodiversity of hawthorn (Crataegus spp.) from the morphological, molecular, and ethnobotanical approaches, and implications for genetic resource conservation in scenery of increasing cultivation: the case of Mexico. Genet Resour Crop Evol 65(3): 897-916. https://doi.org/10.1007/s10722-017-0583-4

3. Bhattacharyya P, Kumaria S, Kumar S, Tandon P (2013) Start Codon Targeted (SCoT) marker reveals genetic diversity of Dendrobium nobile Lindl., an endangered medicinal orchid species. Gene 529(1): 21-26. https://doi.org/10.1016/j.gene.2013.07.096

4. Christensen K I (1992) Revision of Crataegus Sect. Crataegus and Nothosect. Crataeguineae (RosaceaeMaloideae) in the Old World. Syst Bot Monogr 35: 1-199. https://doi.org/10.2307/25027810

5. Collard BCY, Mackill DJ (2008) Start Codon Targeted (SCoT) Polymorphism: A Simple, Novel DNA Marker Technique for Generating Gene-Targeted Markers in Plants. Plant Mol Biol Rep 27(1): 86. https://doi.org/10.1007/s11105-008-0060-5

6. Dai HY, Guo XW, Zhang Y, Li YY, Li H, Zhou CS, Zhang ZH (2008) Genetic diversity of Crataegus pinnatifida Bge. as evaluated by RAPD and ISSR markers. Acta Hortic Sin 35: 1117-1124. https://doi.org/6420/j issn.0513 -353x.2008.08.004

7. Dickinson TA, Belaoussoff S, Love RM, Muniyamma M (1996) North American black-fruited hawthorns. I. Variation in floral construction, breeding system correlates, and their possible evolutionary significance in Crataegus sect. Douglasii London. Folia Geobotanica 31(3): 355-371. 
8. Dickinson TA, Proctor S, Shipley PR, Lee J, Coughlan J, Zarrei M (2014) Natural health products and Crataegus of the Pacific Northwest. Paper presented at the Proceedings of the Annual Meeting. https://www.rom.on.ca/sites/default/files/imce/tadickinson.pdf

9. Dong WX (2013) Technical specifications for crop germplasm characterization and evaluation of Hawthorn. Beijing, China: China Agriculture Press.

10. Dong WX, Li ZX (2015) The Science and Practice of Chinese Fruit Tree: Hawthorn. Shanxi: Science Press.

11. Dönmez EO (2008) Pollen morphology in Turkish Crataegus (Rosaceae). Bot Helv 118(1): 59-70. https://doi.org/10.1007/s00035-008-0823-5

12. Du X, Zhang X, Bo HD, Zhang T C, Lao YC, Dong WX (2019) Molecular analysis of evolution and origins of cultivated hawthorn (Crataegus spp.) and related species in China. Front Plant Sci 10: 443. https://doi.org/10.3389/fpls.2019.00443

13. Earl DA, vonHoldt BM (2012) STRUCTURE HARVESTER: a website and program for visualizing STRUCTURE output and implementing the Evanno method. Conserv Genet Resour 4(2): 359-361. https://doi.org/10.1007/s12686-011-9548-7

14. Edwards JE, Brown PN, Talent N, Dickinson TA, Shipley PR (2012) A review of the chemistry of the genus Crataegus. Phytochemistry 79: 5-26. https://doi.org/10.1016/j.phytochem.2012.04.006

15. Emami A, Shabanian N, Rahmani MS, Khadivi A, Mohammad-Panah N (2018) Genetic characterization of the Crataegus genus: Implications for in situ conservation. Sci Hortic 231: 56-65. https://doi.org/10.1016/j.scienta.2017.12.014

16. Feng, SG, He RF, Jiang MY, Lu JJ, Shen XX, Liu JJ, Wang HZ (2016) Genetic diversity and relationships of medicinal Chrysanthemum morifolium revealed by start codon targeted (SCoT) markers. Sci Hortic 201: 118-123. https://doi.org/10.1016/j.scienta.2016.01.042

17. Guo T, Jiao P (1995) Hawthorn (Crataegus) resources in China. HortScience 30(6): 1132-1134. https://doi.org/10.21273/HORTSCI.30.6.1132

18. Han X, Liang Y, Wang Y, Li F, Guo T, Xue Y (2009) Analysis of the origin and classification of C. brettschnederi by ISSR markers. J Jilin Agric Univ 31(2): 164-167.

19. Hong DY, Blackmore S (2015) Plants of China: A companion to the flora of China: Cambridge University Press.

20. Hu G, Wang Y, Wang Y, Zheng S, Dong W, Dong N (2021) New Insight into the Phylogeny and Taxonomy of Cultivated and Related Species of Crataegus in China, Based on Complete Chloroplast Genome Sequencing. Hortic 7(9): 301. https://doi.org/10.3390/horticulturae7090301

21. Hubisz MJ, Falush D, Stephens M, Pritchard JK (2009) Inferring weak population structure with the assistance of sample group information. Mol Ecol Resour 9(5): 1322-1332. https://doi.org/10.1111/j.17550998.2009.02591.x

22. Igwe DO, Afiukwa CA, Ubi BE, Ogbu KI, Ojuederie OB, Ude GN (2017) Assessment of genetic diversity in Vigna unguiculata L. (Walp) accessions using inter-simple sequence repeat (ISSR) and start codon targeted (SCoT) polymorphic markers. BMC Genet 18(1): 98. https://doi.org/10.1186/s12863-017-0567-6

23. Jiang YL, Dong, WX (2009) Diversity Analysis of Morphological Characters in Hawthorn Germplasm Resources. Northern Fruits 1: 8-10. https://doi.org/10.16376/j.cnki.bfgs.2009.01.022 
24. Khadivi A, Heidari P, Rezaei M, Safari-Khuzani A, Sahebi M (2019) Morphological variabilities of Crataegus monogyna and C. pentagyna in northeastern areas of Iran. Ind Crops Prod 139: 111531. https://doi.org/10.1016/j.indcrop.2019.111531

25. Liu H, Liao K, Liu J, Zhao SR, Sun Q, Cao Q (2016) Analysis of genetic diversity and genetic relationship of wild hawthorn resources in Xinjiang by ISSR markers. Nonwood Forest Research 34(2): 19-23. https://doi.org/10.14067/j.cnki.1003-8981.2016.02.004

26. Lo EYY, Stefanović S, Dickinson TA (2010) Reconstructing reticulation history in a phylogenetic framework and the potential of allopatric speciation driven by polyploidy in an agamic complex in Crataegus (Rosaceae). Evol 64(12): 3593-3608. https://doi.org/10.1111/j.1558-5646.2010.01063.x

27. Long ZJ, Fan LZ, Xu G, Hu SL, Han GH (2015) Application advance of SCoT molecular markers in plants. J Plant Genet Res 16(2): 336-343. https://doi.org/10.13430/j.cnki.jpgr.2015.02.019

28. Lu BR (2014) Genetic and evolutionary effects of hybridization-introgression and their implications for conservation of crop wild relative species. Chinese Science Bulletin 59(6): 479-492. https://doi.org/10.1360/972013-660

29. Pakseresht F, Talebi R, Karami E (2013) Comparative assessment of ISSR, DAMD and SCoT markers for evaluation of genetic diversity and conservation of landrace chickpea (Cicer arietinum L.) genotypes collected from north-west of Iran. Physiol Mol Biol Plants 19(4): 563-574. https://doi.org/10.1007/s12298013-0181-7

30. Peakall R, Smouse P E (2006) GENALEX 6: genetic analysis in Excel. Population genetic software for teaching and research. Mol Ecol Notes 6(1): 288-295. https://doi.org/10.1111/j.1471-8286.2005.01155.x

31. Phipps J, Dvorsky KA (2008) A taxonomic revision of Crataegus series Lacrimatae (Rosaceae). J Bot Res Inst Tex 2: 1101-1162. https://www.jstor.org/stable/41971749

32. Phipps JB (2005) A Review of Hybridization in North American Hawthorns. Another Look at "The Crataegus Problem". Annals of the Missouri Botanical Garden 92(1): 113-126.

33. Phipps JB (2014) Flora of North America Editorial Committee (Eds.), Flora of North America North of Mexico. New York: Oxford University Press.

34. Rohlf FJ (2000) NTSYS-pc: Numerical taxonomy and multivariate analysis system version 2.1. Exeter Software. New York, USA: Setauket.

35. Saboori S, Noormohammadi Z, Sheidai M, Marashi S (2020) SCoT molecular markers and genetic fingerprinting of date palm (Phoenix dactylifera L.) cultivars. Genet Resour Crop Evol 67(1): 73-82. https://doi.org/10.1007/s10722-019-00854-x

36. Sheng F, Chen SY, Tian J, Li P, Qin X, Wang L, Li J (2017) Morphological and ISSR molecular markers reveal genetic diversity of wild hawthorns (Crataegus songorica K. Koch.) in Xinjiang, China. J Integr Agric 16(11): 2482-2495. https://doi.org/10.1016/S2095-3119(17) $\underline{61688-5}$

37. Talent N, Dickinson T (2007) Ploidy level increase and decrease in seeds from crosses between sexual diploids and asexual triploids and tetraploids in Crataegus L.(Rosaceae, Spiraeoideae, Pyreae). Can J Bot 85: $570-584$.

38. Wu F, Zhang Z, Dai H, Zhang Y, Chang, L (2008) Genetic relationship of some Crataegus spp.(Hawthorn) revealed by chloroplast DNA PCR-RFLP. J Biotechnol 136: S103.

https://doi.org/10.1016/j.jbiotec.2008.07.235

Page 11/19 
39. Xiao P, Liu H, Wang D, Tang W, Yang H, Wang C, Tian Y (2020) Assessment of genetic diversity in Camellia oleifera Abel. accessions using inter-simple sequence repeat (ISSR) and start codon targeted (SCoT) polymorphic markers. Genet Resour Crop Evol 67(5): 1115-1124. https://doi.org/10.1007/s10722-02000924-5

40. Yeh FC, Yang RC, Boyle TB (1999) POPGENE v.3.2. The user-friendly shareware for population genetics analysis. University of Alberta, Canadá: Edmonton Molecular Biology and Biotechnology Centre.

41. Zhang X, Zhang Q, Sun X, Du X, Liu W, Dong W (2019) Differential expression of genes encoding phenylpropanoid enzymes in an apricot cultivar (Prunus armeniaca L.) with cleavable endocarp. Trees 33(6): 1695-1710. https://doi.org/10.1007/s00468-019-01890-x

42. Zhao HC, Feng BT (1996) China Fruit-plant Monograph of Hawthorn (Crataegus) Flora. Beijing, China: China Forestry Press.

\section{Tables}

Table 1. Details of biogeographic information for Crataegus resources. 


\begin{tabular}{|c|c|c|c|c|c|}
\hline Species & ID & Biogeographic regions & Species & ID & Biogeographic regions \\
\hline \multirow[t]{14}{*}{ C. bre ${ }^{1}$} & JF1H & Northeast, China & C. $\operatorname{pin}^{4}$ & NMGSLH & North, China \\
\hline & $\mathrm{JF} 2 \mathrm{H}$ & Northeast, China & & WTSSLH & North, China \\
\hline & JF3H & Northeast, China & & YP6H & Northeast, China \\
\hline & $\mathrm{JF} 4 \mathrm{H}$ & Northeast, China & & 1541SLH & Northeast, China \\
\hline & ZF1H & Northeast, China & & MDFSLH & Northeast, China \\
\hline & SF1H & Northeast, China & & CZSLH & Northeast, China \\
\hline & $\mathrm{CH}$ & Northeast, China & & YR5H & Northeast, China \\
\hline & FLH & Northeast, China & & QJX & Northeast, China \\
\hline & HRSLH & Northeast, China & C. hup 5 & $\mathrm{HBSZ2H}$ & Central, China \\
\hline & ZSSLH & Northeast, China & & $\mathrm{HBSZ3H}$ & Central, China \\
\hline & HRSZ & Northeast, China & & $\mathrm{MHL}$ & Central, China \\
\hline & 555 & Northeast, China & & XPZM & Central, China \\
\hline & 82015 & Northeast, China & C. sca ${ }^{6}$ & YNSZ1H & Southwest, China \\
\hline & LNDG & Northeast, China & & YNSZ2H & Southwest, China \\
\hline \multirow[t]{2}{*}{ C. $\max ^{2}$} & MSZ2H & Northeast, China & & YNSZ3H & Southwest, China \\
\hline & MSZ3H & Northeast, China & C. alt ${ }^{7}$ & AETSZ2H & Northwest, China \\
\hline \multirow[t]{3}{*}{ C. $\operatorname{san}^{3}$} & LNSZ1H & Northeast, China & & AETSZ3H & Northwest, China \\
\hline & LNSZ2H & Northeast, China & & & \\
\hline & LNSZ3H & Northeast, China & & & \\
\hline
\end{tabular}

${ }^{1} \mathrm{C}$. bre $=\mathrm{C}$. bretschneideri; ${ }^{2} \mathrm{C} . \max =\mathrm{C}$. maximowiczii; ${ }^{3} \mathrm{C}$. san $=\mathrm{C}$. sanguinea $;{ }^{4} \mathrm{C}$. pin $=\mathrm{C}$. pinnatifida; ${ }^{5} \mathrm{C}$. hup $=$ C. hupehensis ${ }^{6}$ C. sca $=$ C. scabrifolia; ${ }^{7}$ C. alt $=$ C. altaica .

Table 2. Information of SCoT primers used in the present study. 


\begin{tabular}{|c|c|c|c|}
\hline SCoT Marker & Sequences $\left(5^{\prime} \rightarrow 3^{\prime}\right)$ & GC content (\%) & $\operatorname{Tm}\left({ }^{\circ} \mathrm{C}\right)$ \\
\hline SCoT1 & CAACAATGGCTACCACCA & 50 & 54.6 \\
\hline SCoT3 & CAACAATGGCTACCACCG & 56 & 56.0 \\
\hline SCoT4 & CAACAATGGCTACCACCT & 50 & 54.0 \\
\hline SCoT14 & ACGACATGGCGACCACGC & 67 & 62.7 \\
\hline SCoT15 & ACGACATGGCGACCGCGA & 67 & 64.0 \\
\hline SCoT18 & ACCATGGCTACCACCGCC & 67 & 62.2 \\
\hline SCoT22 & AACCATGGCTACCACCAC & 56 & 56.8 \\
\hline SCoT23 & CACCATGGCTACCACCAG & 61 & 57.6 \\
\hline SCoT24 & CACCATGGCTACCACCAT & 56 & 56.3 \\
\hline SCoT28 & CCATGGCTACCACCGCCA & 67 & 62.4 \\
\hline SCoT32 & CCATGGCTACCACCGCAC & 67 & 60.9 \\
\hline SCoT35 & CATGGCTACCACCGGCCC & 72 & 63.8 \\
\hline SCoT36 & GCAACAATGGCTACCACC & 56 & 56.0 \\
\hline $\mathrm{SCoTH}_{1}$ & AACATGGCGACCACCGAC & 61 & 60.4 \\
\hline $\mathrm{SCoTH}_{2}$ & CCATGGCGGCCTCAACAT & 61 & 60.2 \\
\hline $\mathrm{SCOTH}_{3}$ & CAACAATGGCCACCACCA & 56 & 58.3 \\
\hline $\mathrm{SCoTH}_{4}$ & АCAATGGCTCCCACAATC & 50 & 54.7 \\
\hline $\mathrm{SCoTH}_{5}$ & CAACAATGGCGACCTCAA & 50 & 55.5 \\
\hline
\end{tabular}

Table 3. A survey of the total number of bands, number of polymorphic bands, $\% P, P I C$, and $R p$. 


\begin{tabular}{|c|c|c|c|c|c|}
\hline $\begin{array}{l}\text { SCoT } \\
\text { Marker }\end{array}$ & $\begin{array}{l}\text { Total No. of } \\
\text { bands }\end{array}$ & $\begin{array}{l}\text { No. of poly. } \\
\text { bands }\end{array}$ & $\begin{array}{l}\% \text { of poly. Bands } \\
(P)\end{array}$ & $P I C^{1}$ & $\begin{array}{l}\text { Resolving Power } \\
(R p)\end{array}$ \\
\hline SCoT1 & 8 & 8 & 100 & 0.43 & 4.29 \\
\hline SCoT3 & 6 & 6 & 100 & 0.44 & 2.70 \\
\hline SCoT4 & 12 & 9 & 75 & 0.46 & 5.18 \\
\hline SCoT14 & 16 & 16 & 100 & 0.39 & 8.64 \\
\hline SCoT15 & 13 & 13 & 100 & 0.37 & 6.04 \\
\hline SCoT18 & 8 & 5 & 62.5 & 0.49 & 1.34 \\
\hline SCoT22 & 13 & 13 & 100 & 0.50 & 9.88 \\
\hline SCoT23 & 4 & 4 & 100 & 0.41 & 1.44 \\
\hline SCoT24 & 10 & 9 & 90 & 0.49 & 5.27 \\
\hline SCoT28 & 7 & 6 & 85.71 & 0.47 & 3.08 \\
\hline SCoT32 & 11 & 11 & 100 & 0.46 & 7.35 \\
\hline SCoT35 & 8 & 8 & 100 & 0.43 & 3.37 \\
\hline SCoT36 & 3 & 3 & 100 & 0.43 & 0.81 \\
\hline $\mathrm{SCoTH}_{1}$ & 7 & 7 & 100 & 0.45 & 3.63 \\
\hline $\mathrm{SCoTH}_{2}$ & 6 & 6 & 100 & 0.49 & 3.43 \\
\hline $\mathrm{SCoTH}_{3}$ & 10 & 10 & 100 & 0.48 & 4.92 \\
\hline $\mathrm{SCoTH}_{4}$ & 8 & 8 & 100 & 0.44 & 3.99 \\
\hline $\mathrm{SCoTH}_{5}$ & 6 & 6 & 100 & 0.50 & 3.56 \\
\hline Total & 156 & 148 & 94.87 & - & 78.92 \\
\hline Average & - & - & - & 0.45 & - \\
\hline
\end{tabular}

${ }^{1} P I C=$ Polymorphic information content.

Table 4. Genetic diversity and differentiation parameters of Crataegus species. 


\begin{tabular}{|lllllllllll|}
\hline Species & $N_{\mathrm{a}}$ & $N_{\mathrm{e}}$ & $H$ & $l$ & $\mathrm{NPL}$ & $\mathrm{PPL}$ & $H_{\mathrm{t}}$ & $H_{\mathrm{s}}$ & $G_{\mathrm{st}}$ & $N_{\mathrm{m}}$ \\
\hline C. pre & 1.6282 & 1.4279 & 0.2428 & 0.3559 & 98 & 62.82 & & & & \\
\hline C. max & 1.1987 & 1.1405 & 0.0823 & 0.1202 & 31 & 19.87 & & & & \\
\hline C. san & 1.1795 & 1.1509 & 0.0804 & 0.1144 & 28 & 17.95 & & & \\
\hline C. pin & 1.6410 & 1.4580 & 0.2553 & 0.3722 & 100 & 64.10 & & & \\
\hline C. hup & 1.4551 & 1.3095 & 0.1747 & 0.2573 & 71 & 45.51 & & & & \\
\hline C. sca & 1.2500 & 1.1844 & 0.1027 & 0.1493 & 39 & 25.00 & & & & \\
\hline C. alt & 1.2244 & 1.1586 & 0.0929 & 0.1357 & 35 & 22.44 & & & & \\
\hline Total & 1.9487 & 1.5775 & 0.3353 & 0.5005 & 148 & 94.87 & 0.3518 & 0.1473 & 0.5812 & 0.3602 \\
\hline
\end{tabular}

Table 5 Neis genetic identity and genetic distance of Crataegus species ${ }^{1}$.

\begin{tabular}{|c|c|c|c|c|c|c|c|}
\hline Species & C. bre & C. $\max$ & C. san & C. pin & C. hup & C. sca & C. alt \\
\hline C. bre & 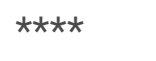 & 0.7826 & 0.7420 & 0.8655 & 0.8530 & 0.7624 & 0.6860 \\
\hline C. $\max$ & 0.2451 & 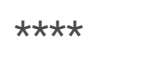 & 0.8079 & 0.7480 & 0.7003 & 0.6059 & 0.5962 \\
\hline C. san & 0.2983 & 0.2134 & 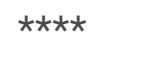 & 0.7532 & 0.6790 & 0.6268 & 0.7090 \\
\hline C. pin & 0.1444 & 0.2904 & 0.2835 & 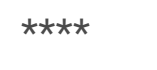 & 0.8986 & 0.7232 & 0.6881 \\
\hline C. hup & 0.1590 & 0.3562 & 0.3871 & 0.1069 & 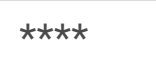 & 0.7784 & 0.6406 \\
\hline C. sca & 0.2712 & 0.5011 & 0.4672 & 0.3241 & 0.2505 & 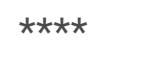 & 0.5804 \\
\hline C. alt & 0.3769 & 0.5172 & 0.3438 & 0.3738 & 0.4453 & 0.5440 & $\star \star \star \star$ \\
\hline
\end{tabular}

${ }^{1}$ Neis genetic identity (above diagonal) and genetic distance (below diagonal). C. bre $=$ C. bretschneideri; $C$. max $=C$. maximowiczii; $C$. san $=C$. sanguinea; $C$. pin $=C$. pinnatifida; $C$. hup $=C$. hupehensis; $C . s c a=C$. scabrifolia; C. alt= C. altaica.

\section{Figures}

Figure 1

Phenotypic traits of leaf, flower, and mature fruit of Crataegus individuals $C$. bretschneideri - SF1H, $C$. maximowiczii - MSZ2H, C. sanguinea - LNSZ1H, C. pinnatifida - MDFSLH, C. hupehensis - HBSZ2H, C. 


\section{Figure 2}

Quantitative traits of leaf, flower, and mature fruit of Crataegus individuals Error bars indicate the standard deviation of twenty biological replications. ${ }^{\text {abcd }}$ Means in the bar with different superscripts differs significantly. C. bre $=$ C. bretschneideri, C. $\max =$ C. maximowiczii, C. san $=C$. sanguinea, $C$. pin $=$ C. pinnatifida, $C$. hup $=C$. hupehensis, C. sca= C. scabrifolia, C. alt= C. altaica.

\section{Figure 3}

Cluster analysis of Crataegus individuals based on phenotypic data (A) Cluster analysis using phenotypic traits data of Crataegus leaves, (B) Cluster analysis based on phenotypic traits data of Crataegus flowers, (C) Cluster analysis accord to phenotypic traits data of Crataegus fruits, (D) Cluster analysis depend on phenotypic traits data of Crataegus leaves, flowers, and fruits. The names of individuals are given next to their branches. $C$. bre $=$ C. bretschneideri, $C$. $\max =C$. maximowiczii, $C$. san $=C$. sanguinea, $C$. pin $=C$. pinnatifida, $C$. hup $=C$. hupehensis, C. sca= C. scabrifolia, C. alt $=$ C. altaica.

|C. bre |C.pin |C.hup |C.sca |C.max |C.san |C.alt

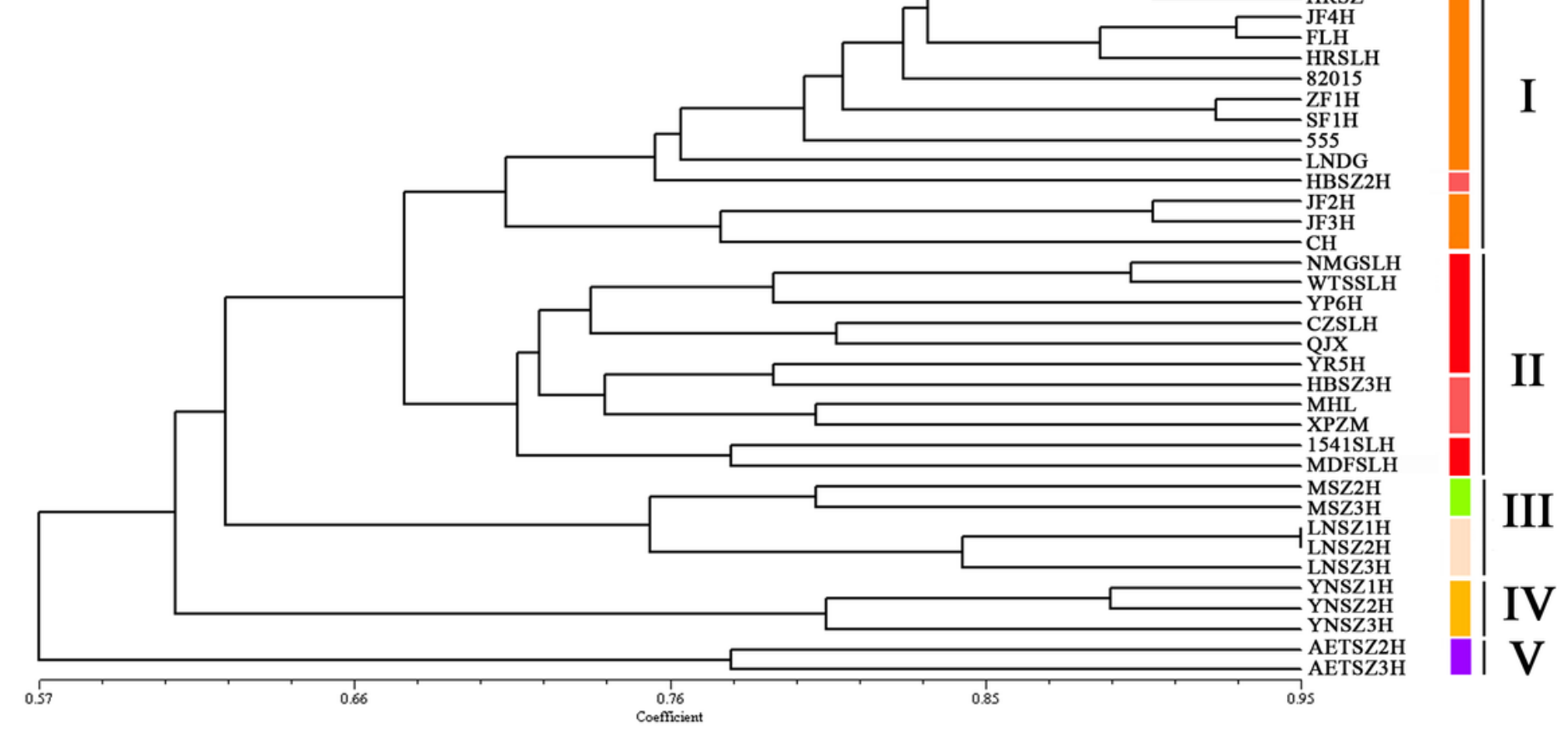

Figure 4

Dendrogram of Crataegus individuals based on SCOT polymorphism The resulting genetic similarity indices were used for generating the cluster tree through the UPGMA method. The names of individuals are given next 
to their branches. $C$. bre $=$ C. bretschneideri, $C$. max $=$ C. maximowiczii, $C$. san $=C$. sanguinea, $C$. pin $=C$. pinnatifida, $C$. hup $=$ C. hupehensis, C. sca $=$ C. scabrifolia, C. alt= C. altaica.

\section{Figure 5}

Scatter plot of Crataegus individuals based on Principal Coordinate Analysis (PCoA) of SCoT markers $C$. bre $=$ C. bretschneideri, C. $\max =$ C. maximowiczii, C. san $=$ C. sanguinea, $C$. pin $=$ C. pinnatifida, $C$. hup $=C$. hupehensis, C. sca= C. scabrifolia, C. alt= C. altaica.
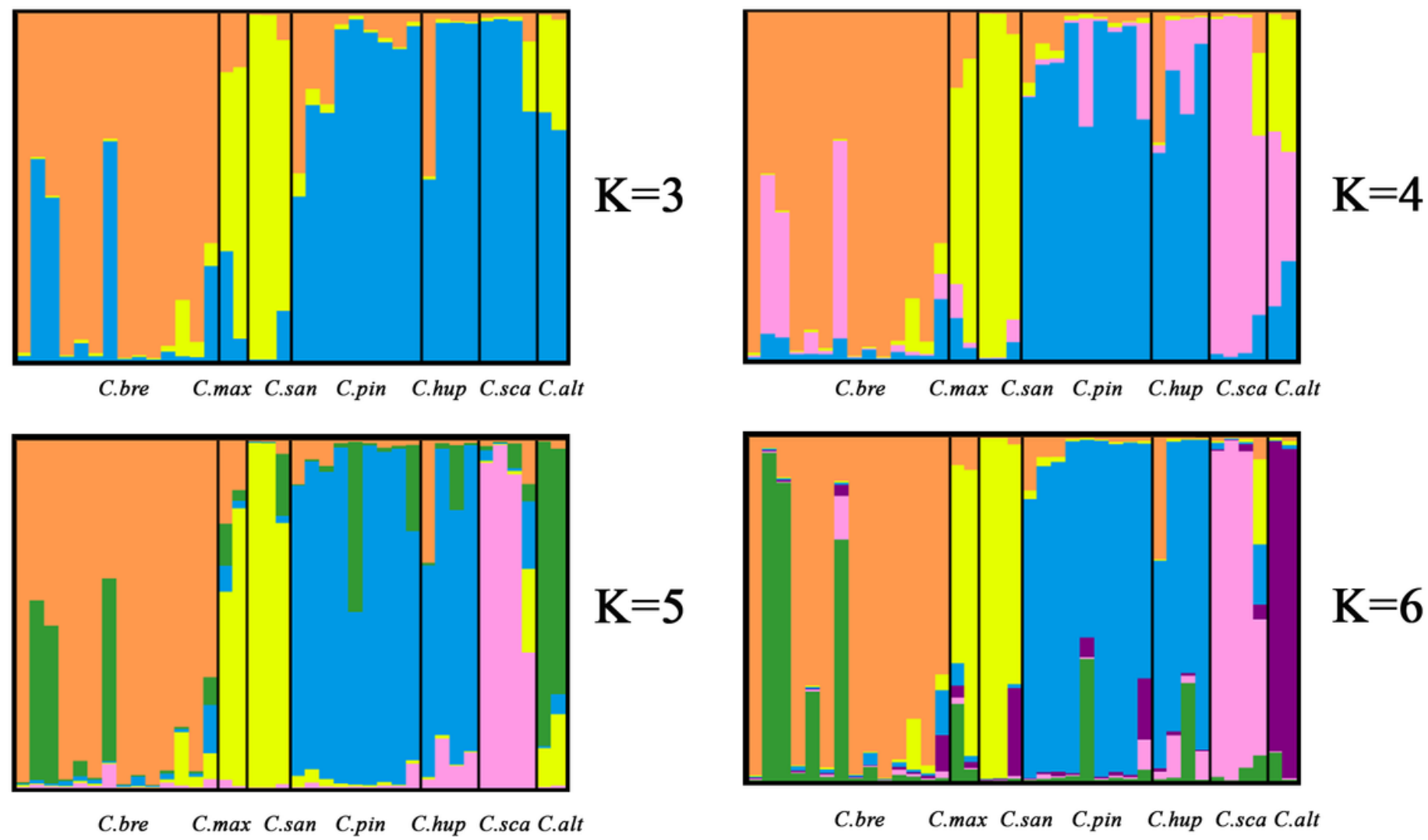

Figure 6

Population structure $(K=3, K=4, K=5$, and $K=6)$ of thirty-six individuals from seven Crataegus species based on SCoT markers The Structure was run ten times for each $K$ value from 1 to 7 for determining the most likely number of ancestral kinships $(K)$. Each vertical bar represents Crataegus individual. Each color represents one putative ancestral background. $C$. bre $=C$. bretschneideri,$C$. max $=C$. maximowiczii, $C$. san $=C$. sanguinea, $C$. pin $=$ C. pinnatifida, $C$. hup $=$ C. hupehensis, $C$. sca $=$ C. scabrifolia, C. alt $=$ C. altaica.

\section{Supplementary Files}

This is a list of supplementary files associated with this preprint. Click to download. 
- SupplementaryFig.S1.tif

- SupplementaryFig.S2.tif

- SupplementaryTableS1.xIsx

- SupplementaryTableS2.xIsx

- SupplementaryTableS3.xIsx

- SupplementaryTableS4.xIsx

- SupplementaryTableS5.xIsx

- SupplementaryTableS6.xIsx

- SupplementaryTableS7.xIsx

- SupplementaryTableS8.xlsx 